\title{
Prevalence of depression in patients with Diabetes Mellitus Type 2 (DM) and Chronic Obstructive Pulmonary Disease (COPD)
}

\author{
Vineet Jalota ${ }^{1}$, Sathyanarayana $\mathrm{MT}^{2} *$, Dhanashree Akshatha ${ }^{3}$, \\ Swarna Buddha Nayok ${ }^{4}$
}

\section{ABSTRACT}

Introduction: Depression has been bi-directionally associated with chronic medical disorders such as Diabetes Mellitus type 2(DM) and Chronic Obstructive Pulmonary Disease(COPD). Presence of depression complicates the treatment outcomes due to poor adherence to treatment regimens and is also associated with significant functional impairment ranging from impaired productivity to absenteeism. Aims: To estimate the prevalence of depression in patients with DM and COPD, and correlate them with socio-demographic variables. Settings and Design: A cross sectional hospital-based study was conducted on 30 patients having DM and 30 patients having COPD from January 2018 to June 2018. Methods and Material: Socio-demographic data was collected using semi-structured proforma and depression was assessed using Hamilton Depression Rating Scale (HAM-D). Statistical analysis used: Quantitative data is expressed in numbers and percentages. Pearson's Chisquare was applied to compare the sociodemographic correlates amongst themselves with diagnosis of DM and COPD. Results: Prevalence of depression in patients with DM was $63.33 \%$ and in those with COPD was $66.67 \%$. Socio-demographically, only living status was significant with DM ( $\mathrm{p}=0.069)$. Overall, most $(56.41 \%)$ had mild levels of severity. Conclusions: In about two-thirds of patients having DM or COPD, psychiatric co-morbidity in the form of depression is present. Hospital admission due to acute exacerbation may lead to increase in depressive features. This may contribute to poor compliance to treatment of these medical illnesses subsequently. Thus, special measures for early detection and treatment of depression in patients with these medical co-morbidities should be implemented to enhance treatment outcome.

Keywords: Diabetes Mellitus, Chronic Obstructive Pulmonary Disease, Depression

\footnotetext{
${ }^{1}$ Junior Resident, Department of Psychiatry, Sri Siddhartha medical College and Research Centre, Tumakuru, Karnataka, India

${ }^{2}$ Professor and Head, Department of Psychiatry, Sri Siddhartha medical College and Research Centre, Tumakuru, Karnataka, India

${ }^{3}$ Assistant Professor, Department of Psychiatry, Sri Siddhartha medical College and Research Centre, Tumakuru, Karnataka, India

${ }^{4}$ Junior Resident, Department of Psychiatry, Sri Siddhartha medical College and Research Centre, Tumakuru, Karnataka, India

*Responding Author
}

Received: March 5, 2019; Revision Received: April 1, 2019; Accepted: July 25, 2019

(C) 2019, Jalota. V., Sathyanarayana MT., Akshatha. D., \& Swarna. B.N.; licensee IJIP. This is an Open Access Research distributed under the terms of the Creative Commons Attribution License (www.creativecommons.org/licenses/by/2.0), which permits unrestricted use, distribution, and reproduction in any Medium, provided the original work is properly cited. 


\section{Prevalence of depression in patients with Diabetes Mellitus Type 2 (DM) and Chronic Obstructive Pulmonary Disease (COPD)}

Chronic medical disorders (CMD) are major causes for worldwide disability and mortality. They may be accounting for 36 million deaths out of 56 million deaths from 2008. Contrary to popular beliefs, NCD is not restricted to affluent countries. They are quite common in low income countries and 80\% deaths in NCD belong from here. This is particularly seen in cases with Type 2 Diabetes Mellitus (DM) and Chronic Obstructive Pulmonary Disease (COPD)(1). This significantly affects the course and outcome. When co-morbid with CMD, it is associated with significant functional impairment through reduced work functioning, absenteeism and decreased productivity(Simon et al., 2007). Depression and anxiety often complicate the treatment outcomes due to poor adherence to treatment regimens(Gonzalez et al., 2008; Simon et al., 2007). Both DM and COPD are leading causes of death worldwide. The prevalence of depression is also steadily increasing. World Health Organization (WHO) predicts it to first in global burden of disease by 2030 (Kaplan \& Sadock, 1998).

Aetiologically, depression is bi-directionally associated with chronic medical illnesses(Gahlan, Rajput, Gehlawat, \& Gupta, 2018; Golden et al., 2008). Pooled prevalence however shows a lower rate of 38\%(Hussain, Habib, Singh, Akhtar, \& Najmi, 2018). In those above the age of 60 years, it is 6\%(Subramaniam et al., 2017). Thus, we can estimate that a large number of diabetic patients are also at risk to develop depression. Sleep disturbances in COPD increase depressive symptoms(De, 2012). COPD has cumulative prevalence of $72 \%$, but this may be due to other confounding factors (De, 2011). A reasonably better estimate of prevalence is $28.4 \%$ (Chaudhary et al., 2016). One in every five COPD patients will have signs of depression(Mehta et al., 2014).This shows that evaluation of depression and anxiety, even if sub-syndromal, is essential in patients with DM and COPD. In this study, we try to estimate the prevalence of depression in such patients who are hospitalized.

\section{MATERIALS AND METHODS}

Participants: This cross-sectional study was done in a tertiary hospital. Patients admitted under the department of General Medicine from $1^{\text {st }}$ January 2018 to $30^{\text {th }}$ June 2018 with the diagnosis of either DM or COPD from at least last three months were included. Those having any other comorbid medical/surgical diagnosis was excluded. Patients with either gender aged between 19 to 60 years were included only after obtaining informed written consent from them. We also excluded patients with symptoms suggestive of delirium and/or dementia or those who were previously diagnosed to have any psychiatric illness. Sample size of patients with DM and COPD was 30 each.

Tools: Sociodemographic details and clinical profile for DM and COPD were obtained through a semi-structured questionnaire. The primary investigator (PI) assessed the patients for symptoms of depression by using Hamilton Depression Rating Scale (HAM-D). HAM-D is a standardised rating scale, focussing more on somatic complaints. We chose this scale as it would be suitable to assess somatic symptoms in patients with CMD. Internal consistency of HAM-D is 0.83 and test-retest reliability is 0.93 .

Procedure: Our objectives were to estimate the prevalence of depression in admitted patients with DM or COPD, and to correlate prevalence to sociodemographic data. Institutional Ethical clearance was obtained and any doubts regarding the questionnaire were clarified immediately. Anonymity was explained. After obtaining informed consent, PI interviewed the patients for assessments of the scales. 
Prevalence of depression in patients with Diabetes Mellitus Type 2 (DM) and Chronic Obstructive Pulmonary Disease (COPD)

Statistical analysis: Data collected was computed and analysed using Epi Info. Quantitative data is expressed in numbers and percentages. Pearson's Chi-square was applied to compare the sociodemographic correlates amongst themselves with diagnosis of DM and COPD.

\section{RESULTS}

Sociodemographic correlates of DM and COPD are presented in Table 1 and Table 2 respectively.

Table 1: Sociodemographic correlates for patients with DM and depression

\begin{tabular}{|c|c|c|c|}
\hline (a) & No Depression & Depression & $p$-value \\
\hline \multicolumn{4}{|l|}{ Religion } \\
\hline Hindu & 8 & 13 & \multirow[t]{2}{*}{0.804} \\
\hline Muslim & 3 & 6 & \\
\hline \multicolumn{4}{|l|}{ Marital Status } \\
\hline Single & 1 & 0 & \multirow{4}{*}{0.129} \\
\hline Married & 10 & 13 & \\
\hline Divorced & 0 & 2 & \\
\hline Widowed & 0 & 4 & \\
\hline \multicolumn{4}{|l|}{ Education } \\
\hline Illiterate & 0 & 2 & \multirow{6}{*}{0.564} \\
\hline Primary School & 2 & 4 & \\
\hline Middle School & 2 & 6 & \\
\hline High School & 5 & 6 & \\
\hline Post High School & 1 & 1 & \\
\hline Graduate/ Post Graduate & 1 & 0 & \\
\hline \multicolumn{4}{|l|}{ Employment Status } \\
\hline Unemployed & 2 & 6 & \multirow{7}{*}{0.260} \\
\hline Unskilled Worker & 2 & 7 & \\
\hline Semi-Skilled Worker & 4 & 6 & \\
\hline Skilled Worker & 1 & 0 & \\
\hline Clerical & 1 & 0 & \\
\hline Semi Profession & 1 & 0 & \\
\hline Profession & 0 & 0 & \\
\hline \multicolumn{4}{|l|}{ Monthly Income } \\
\hline$<1802$ & 4 & 11 & \multirow{4}{*}{0.206} \\
\hline $1802-5386$ & 4 & 5 & \\
\hline $5387-8988$ & 1 & 3 & \\
\hline 8989-13499 & 2 & 0 & \\
\hline \multicolumn{4}{|l|}{ Living With } \\
\hline Parents & 2 & 0 & \multirow{4}{*}{$0.069 *$} \\
\hline Alone & 0 & 3 & \\
\hline Spouse \& Child & 9 & 13 & \\
\hline Other & 0 & 3 & \\
\hline
\end{tabular}

* = p value significant (<0.05), Pearson's Chi Square Test 
Prevalence of depression in patients with Diabetes Mellitus Type 2 (DM) and Chronic Obstructive Pulmonary Disease (COPD)

Table 2: Sociodemographic correlates for patients with COPD and depression

\begin{tabular}{|c|c|c|c|}
\hline & No Depression & Depression & $p$-value \\
\hline \multicolumn{4}{|l|}{ Gender } \\
\hline Male & $9(31.0 \%)$ & $20(69.0 \%)$ & \multirow[t]{2}{*}{0.150} \\
\hline Female & $1(100.0 \%)$ & $0(0 \%)$ & \\
\hline \multicolumn{4}{|l|}{ Religion } \\
\hline Hindu & 9 (37.5\%) & $15(62.5 \%)$ & \multirow[t]{2}{*}{0.333} \\
\hline Muslim & $1(16.7 \%)$ & $5(83.3 \%)$ & \\
\hline \multicolumn{4}{|l|}{ Marital Status } \\
\hline Single & $1(100.0 \%)$ & $0(0 \%)$ & \multirow{4}{*}{0.282} \\
\hline Married & $9(32.1 \%)$ & $19(67.9 \%)$ & \\
\hline Divorced & $0(0 \%)$ & $0(0 \%)$ & \\
\hline Widowed & $0(0 \%)$ & $1(100.0 \%)$ & \\
\hline \multicolumn{4}{|l|}{ Education } \\
\hline Illiterate & $0(0 \%)$ & $3(100.0 \%)$ & \multirow{6}{*}{0.184} \\
\hline Primary School & $2(40.0 \%)$ & $3(60.0 \%)$ & \\
\hline Middle School & $7(53.8 \%)$ & $6(46.2 \%)$ & \\
\hline High School & $1(14.3 \%)$ & $6(85.7 \%)$ & \\
\hline Post High School & $0(0 \%)$ & $2(100.0 \%)$ & \\
\hline Graduate/ Post Graduate & $0(0 \%)$ & $0(0 \%)$ & \\
\hline \multicolumn{4}{|l|}{ Employment Status } \\
\hline Unemployed & $2(66.7 \%)$ & $1(33.3 \%)$ & \multirow{7}{*}{0.613} \\
\hline Unskilled Worker & $5(29.4 \%)$ & $12(70.6 \%)$ & \\
\hline Semi-Skilled Worker & $3(37.5 \%)$ & $5(62.5 \%)$ & \\
\hline Skilled Worker & $0(0 \%)$ & $1(100.0 \%)$ & \\
\hline Clerical & $0(0 \%)$ & $1(100.0 \%)$ & \\
\hline Semi Profession & $0(0 \%)$ & $0(0 \%)$ & \\
\hline Profession & $0(0 \%)$ & $0(0 \%)$ & \\
\hline \multicolumn{4}{|l|}{ Monthly Income } \\
\hline$<1802$ & $6(37.5 \%)$ & $10(62.5 \%)$ & \multirow{4}{*}{0.248} \\
\hline $1802-5386$ & $4(50.0 \%)$ & $4(50.0 \%)$ & \\
\hline $5387-8988$ & $0(0 \%)$ & $4(100.0 \%)$ & \\
\hline 13495-17999 & $0(0 \%)$ & $2(100.0 \%)$ & \\
\hline \multicolumn{4}{|l|}{ Living With } \\
\hline Parents & $1(100.0 \%)$ & $0(0 \%)$ & \multirow{4}{*}{0.284} \\
\hline Alone & $0(0 \%)$ & $1(100.0 \%)$ & \\
\hline Spouse \& Child & $9(32.1 \%)$ & $19(67.9 \%)$ & \\
\hline Other & $0(0 \%)$ & $0(0 \%)$ & \\
\hline
\end{tabular}

Prevalence of depression in patients with DM was 63.33\% and in those with COPD was $66.67 \%$. Out of the 19 patients with DM who had depression, nine had mild (47.36\%), four had moderate (21.05\%), four had severe $(21.05 \%)$ and two had very severe levels $(10.52 \%)$ of depression. Out of the 20 patients with COPD who had depression, 13 had mild (65\%), six had moderate (30\%) and one had very severe (5\%) levels of depression.

\section{DISCUSSION}

Prevalence of depression in DM patients have shown large variability. When Patient Health Questionnaire (PHQ-9) was applied on outpatients of DM, depression was found in only 13\%

(C) The International Journal of Indian Psychology, ISSN 2348-5396 (e)| ISSN: 2349-3429 (p) | 7 


\section{Prevalence of depression in patients with Diabetes Mellitus Type 2 (DM) and Chronic Obstructive Pulmonary Disease (COPD)}

(Dejenie Habtewold, Radie, \& Sharew, 2015). Assessment on outpatients using a better tool as Major Depression Inventory (MDI) showed 38.8\% of stable DM patients having depression, majority (25\%) of them having mild(Mathew, Dominic, Isaac, \& Jacob, 2012). When Beck's Depressive Inventory (BDI) is used on outpatients with DM, prevalence was 38.8\%(Roy et al., 2018). Using gold standard HAM-D and Hamilton Anxiety Rating Scale (HAM-A) on outpatients with matched controls, one study found $26.3 \%$ had depression, 27.6\% had anxiety and 21\% had both depression and anxiety (Rajput, Gehlawat, Gehlan, Gupta, \& Rajput, 2016). However, even using PHQ-9, higher rates of depression (63\%) was found in those with duration of DM more than five years and poor glycaemic control(Bahety et al., 2017). This shows that not only appropriate scales, but current status of DM is also important while assessing for depressive symptoms.

One study found depression in $49.2 \%$ of patients of stable COPD attending outpatients. Majority of them had moderate to severe depressive illness, followed closely by mild symptoms. However, Patient Health Questionnaire (PHQ-9) was used here (12). When better tools like HAM-D and State Trait Anxiety Inventory (STAI) were used in stable outpatients, anxiety and depression was found to be in 42.6\% (Biswas et al., 2017). Lower rates of depression (13.2\%) and anxiety (20.6\%) were seen in another study done on stable chronic respiratory illnesses patients visiting outpatient clinic. Computer assisted Global Mental Health Assessment Tool, Primary Care Version (GMHAT/PC) was used here, which again is not standardized for assessment of depression (Sharma et al., 2013). While this approach may be suitable for areas with less infrastructure, standardized assessment is emphasized in admitted patients. Current status of COPD may influence depressive symptoms. In one study, outpatients were evaluated by Hospital Anxiety and Depression Scale (HADS) as screening and then evaluation by psychiatrist. Depression was found in only $22.7 \%$. Again, lower rate may lie within the current status of COPD. In this sample, only $17.5 \%$ of those who had psychiatric illnesses were hospitalized in the previous one year, compared to $12.5 \%$ of those without psychiatric illnesses(Dua et al., 2018). When patients with acute exacerbations were evaluated, 38.7\% had depression as assessed by HADS, being the second most common comorbidity, first being gastroesophageal reflux disease (GERD) at $80 \%(17)$. Severity of COPD and psychiatric comorbidities also increase with each other (Chaudhary et al., 2016; Mehta et al., 2014).

We addressed two problems of CMD and depression in our study, use of standard scale and current status of CMD. We found prevalence of both DM and COPD to be high. About twothirds of the patients of each group had depressive symptoms. Most (56.41\%) of them had mild severity. High prevalence is seen here as we took patients who were admitted for DM or COPD. We also used HAM-D for assessment which is standardized for depression and also interviewer rated. Admitted patients in our study were those who had exacerbation, as they were already detected to have DM or COPD at least from last three months. They also tend to have more severity of the medical illnesses. Thus, they report of more depressive symptoms. Evaluation for depressive symptoms needs to be done at this stage where disability is increased. Further, adequate interventions at this period, even simple psycho-education regarding CMD and depression can have a positive impact on the outcome by improving compliance and decreasing hospital stay (Gonzalez et al., 2008; Poongothai et al., 2017; Simon et al., 2007). We did not find significant correlations of sociodemographic factors with depression, apart from "living status" in patients with DM. This implies that sociodemographic factors may not play a significant role in depressive symptoms when there is an exacerbation of CMD, or there is a need for hospital admission. Also, none of these

(c) The International Journal of Indian Psychology, ISSN 2348-5396 (e)| ISSN: 2349-3429 (p) | 8 


\section{Prevalence of depression in patients with Diabetes Mellitus Type 2 (DM) and Chronic Obstructive Pulmonary Disease (COPD)}

patients were referred to psychiatry department of evaluation. While mild symptoms may be missed, seven patients in total $(11.67 \%)$ had severe or very severe symptoms. This shows that depressive symptoms are either ignored, missed or not adequately evaluated in patients with CMD.

Evaluation of admitted patients, of most common CMD, using standardized tool are the strengths of this study. We stress on that admitted patients are more prone to develop depressive symptoms. However, a larger sample size and subsequent follow up of these patients will be useful in future. Prospective assessment and comparison of depression during stable phases and exacerbations of CMD will give us better idea regarding their association. Nonetheless, this study emphasises that every admitted patient with CMD may benefit from timely and adequate assessment of depression. This should be done with standardized scales and irrespective of their sociodemographic status. We should also take steps to bring importance of this to the notice of physicians, as addition of evaluation and intervention of depression will reduce the overall burden and disability.

\section{REFERENCES}

Bahety, P., Agarwal, G., Khandelwal, D., Dutta, D., Kalra, S., Taparia, P., \& Singhal, V. (2017). Occurrence and Predictors of Depression and Poor Quality of Life among Patients with Type-2 Diabetes: A Northern India Perspective. Indian Journal of Endocrinology and Metabolism, 21(4), 564-569. https://doi.org/10.4103/ijem.IJEM_123_17

Bhatia, A., Prakash, V., Kant, S., \& Verma, A. K. (2016). A search for covert precipitating clinical parameters in frequent exacerbators of chronic obstructive pulmonary disease. Lung India: Official Organ of Indian Chest Society, 33(6), 600-604. https://doi.org/10.4103/0970-2113.192877

Biswas, D., Mukherjee, S., Chakroborty, R., Chatterjee, S., Rath, S., Das, R., \& Begum, S. (2017). Occurrence of Anxiety and Depression among Stable COPD Patients and its Impact on Functional Capability. Journal of Clinical and Diagnostic Research: JCDR, 11(2), OC24-OC27. https://doi.org/10.7860/JCDR/2017/24203.9393

Chaudhary, S. C., Nanda, S., Tripathi, A., Sawlani, K. K., Gupta, K. K., Himanshu, D., \& Verma, A. K. (2016). Prevalence of psychiatric comorbidities in chronic obstructive pulmonary disease patients. Lung India: Official Organ of Indian Chest Society, 33(2), 174-178. https://doi.org/10.4103/0970-2113.177441

De, S. (2011). Prevalence of depression in stable chronic obstructive pulmonary disease. The Indian Journal of Chest Diseases \& Allied Sciences, 53(1), 35-39.

De, S. (2012). Subjective assessment of quality of sleep in chronic obstructive pulmonary disease patient and its relationship with associated depression. Lung India: Official Organ of Indian Chest Society, 29(4), 332-335. https://doi.org/10.4103/09702113.102808

Dejenie Habtewold, T., Radie, Y. T., \& Sharew, N. T. (2015). Prevalence of Depression among Type 2 Diabetic Outpatients in Black Lion General Specialized Hospital, Addis Ababa, Ethiopia. Depression Research and Treatment, 2015. https://doi.org/10.1155/2015/184902

Dua, R., Das, A., Kumar, A., Kumar, S., Mishra, M., \& Sharma, K. (2018). Association of comorbid anxiety and depression with chronic obstructive pulmonary disease. Lung India: Official Organ of Indian Chest Society, 35(1), 31-36. https://doi.org/10.4103/lungindia.lungindia_537_16 
Gahlan, D., Rajput, R., Gehlawat, P., \& Gupta, R. (2018). Prevalence and determinants of diabetes distress in patients of diabetes mellitus in a tertiary care centre. Diabetes \& Metabolic Syndrome, 12(3), 333-336. https://doi.org/10.1016/j.dsx.2017.12.024

Golden, S. H., Lazo, M., Carnethon, M., Bertoni, A. G., Schreiner, P. J., Diez Roux, A. V., Lyketsos, C. (2008). Examining a bidirectional association between depressive symptoms and diabetes. JAMA, 299(23), 2751-2759. https://doi.org/10.1001/jama.299.23.2751

Gonzalez, J. S., Peyrot, M., McCarl, L. A., Collins, E. M., Serpa, L., Mimiaga, M. J., \& Safren, S. A. (2008). Depression and Diabetes Treatment Nonadherence: A MetaAnalysis. Diabetes Care, 31(12), 2398-2403. https://doi.org/10.2337/dc08-1341

Hussain, S., Habib, A., Singh, A., Akhtar, M., \& Najmi, A. K. (2018). Prevalence of depression among type 2 diabetes mellitus patients in India: A meta-analysis. Psychiatry Research, 270, 264-273. https://doi.org/10.1016/j.psychres.2018.09.037

Kaplan, H. I., \& Sadock, B. J. (1998). Kaplan and Sadock's synopsis of psychiatry: Behavioral sciences/clinical psychiatry, 8th ed. Baltimore, MD, US: Williams \& Wilkins Co.

Mathew, C. S., Dominic, M., Isaac, R., \& Jacob, J. J. (2012). Prevalence of depression in consecutive patients with type 2 diabetes mellitus of 5-year duration and its impact on glycemic control. Indian Journal of Endocrinology and Metabolism, 16(5), 764-768. https://doi.org/10.4103/2230-8210.100671

Mehta, J. R., Ratnani, I. J., Dave, J. D., Panchal, B. N., Patel, A. K., \& Vala, A. U. (2014). Association of psychiatric co-morbidities and quality of life with severity of chronic obstructive pulmonary disease. East Asian Archives of Psychiatry: Official Journal of the Hong Kong College of Psychiatrists = Dong Ya Jing Shen Ke Xue Zhi: Xianggang Jing Shen Ke Yi Xue Yuan Qi Kan, 24(4), 148-155.

Poongothai, S., Anjana, R. M., Radha, S., Sundari, B. B., Shanthi Rani, C. S., \& Mohan, V. (2017). Epidemiology of Depression and its Relationship to Diabetes in India. The Journal of the Association of Physicians of India, 65(8), 60-66.

Rajput, R., Gehlawat, P., Gehlan, D., Gupta, R., \& Rajput, M. (2016). Prevalence and predictors of depression and anxiety in patients of diabetes mellitus in a tertiary care center. Indian Journal of Endocrinology and Metabolism, 20(6), 746-751. https://doi.org/10.4103/2230-8210.192924

Roy, M., Sengupta, N., Sahana, P. K., Das, C., Talukdar, P., Baidya, A., \& Goswami, S. (2018). Type 2 diabetes and influence of diabetes-specific distress on depression. Diabetes Research and Clinical Practice, 143, 194-198. https://doi.org/10.1016/j.diabres.2018.07.006

Sharma, B. B., Singh, S., Sharma, V. K., Choudhary, M., Singh, V., Lane, S., ... Copeland, J. (2013). Psychiatric morbidity in chronic respiratory disorders in an Indian service using GMHAT/PC. General Hospital Psychiatry, 35(1), 39-44. https://doi.org/10.1016/j.genhosppsych.2012.09.009

Simon, G. E., Katon, W. J., Lin, E. H. B., Rutter, C., Manning, W. G., Von Korff, M., ... Young, B. A. (2007). Cost-effectiveness of systematic depression treatment among people with diabetes mellitus. Archives of General Psychiatry, 64(1), 65-72. https://doi.org/10.1001/archpsyc.64.1.65

Subramaniam, M., Abdin, E., Vaingankar, J. A., Picco, L., Seow, E., Chua, B. Y., ... Chong, S. A. (2017). Comorbid Diabetes and Depression among Older Adults - Prevalence, Correlates, Disability and Healthcare Utilisation. Annals of the Academy of Medicine, Singapore, 46(3), 91-101. 

Pulmonary Disease (COPD)

\section{Acknowledgements}

The authors profoundly appreciate all the people who have successfully contributed in ensuring this paper in place. Their contributions are acknowledged however their names cannot be mentioned.

\section{Conflict of Interest}

No conflict of interests.

How to cite this article: Jalota. V., Sathyanarayana MT., Akshatha. D., \& Swarna. B.N. (2019). Prevalence of depression in patients with Diabetes Mellitus Type 2 (DM) and Chronic Obstructive Pulmonary Disease (COPD). International Journal of Indian Psychology, 7(3), 4-11. DIP:18.01.002/20190703, DOI:10.25215/0703.002 